\title{
Starch Concentrations in Log-Grown Shiitake Mushrooms (Lentinula edodes (Berk.) Pegler)
}

\author{
David Brauer ${ }^{*}, 1$, Tom E. Kimmons ${ }^{2}$, Mark Phillips ${ }^{2}$ and Diana Brauer ${ }^{3}$ \\ ${ }^{I}$ Conservation and Production Research Laboratory, ARS-USDA, P.O. Drawer 10, 2300 Experiment Station Rd, \\ Bushland TX 79012, USA \\ ${ }^{2}$ Shirley Community Development Corporation, 366 Brown Rd, Shirley, AR 72153, USA \\ ${ }^{3}$ Dale Bumpers Small Farms Research Center, ARS-USDA, 6883 Highway 23, Booneville AR 72927, USA
}

\begin{abstract}
Shiitake (Lentinula edodes (Berk.) Pegler) mushrooms have a reputation as a healthy food, in part from the abundance of different polysaccharides that may have functional food activities. However, the total polysaccharide content of mushrooms may not represent the functional food activity if they contain significant concentrations of starch. There are few reports characterizing the starch content of shiitakes. This report summarizes several studies that examined the effects of shiitake strains, mushroom cap development, inoculated tree log species, and length of saprophytic association on the starch concentrations. Starch concentrations in shiitake mushrooms varied between 20 and $100 \mathrm{mg} \mathrm{g}^{-1}$ tissue (dry weight basis). Results indicate that the starch concentrations in shiitake mushrooms are influenced by the spawn source, the characteristics of the environment and the interaction between fungal phenotypes and environment. General trends include: 1) mushrooms harvested at more immature stages of development (during bud break or before veil break) tended to have lower starch concentrations; and 2) the initial harvests of mushrooms from an inoculated log tended to have higher starch concentrations.
\end{abstract}

Keywords: Enzymatic analysis, mushroom, cap development, phenotype by environment interaction, polysaccharide, saprophytic association.

\section{INTRODUCTION}

Shiitake (Lentinula edodes (Berk.) Pegler) mushroom production in the United States has expanded several-fold over the last 30 years [1]. Demand for shiitakes as food and as health promoting products has also increased. Worldwide sales of medicinal mushroom products in 2000 exceeded \$US 10 billion [2]. Worldwide sales of medicinal mushroom products have probably increased since 2003, when skin care products made from shiitakes were first sold [3]. Sales of medicinal mushrooms in the United States are only a fraction of the worldwide market, estimated to be only \$US 40 million in 2006 [4]. Likewise, production of American medicinal mushrooms, estimated to be $4,000 \mathrm{Mg}$ in 2006, was only a fraction of the $400,000 \mathrm{Mg}$ of Agaricus species produced that year [4]. However, large increases in medicinal mushroom production were noted between 2005 and 2006. Shiitakes represented about half of the non-Agaricus mushroom production in the United States between 2007 and 2009 [5].

Fungal polysaccharides have been identified as promoting human health [6]. One of the reported beneficial effects of fungal glucans is stimulation of the immune system [7-9]. Sales of mushroom-based immune boosters

*Address correspondence to this author at Conservation and Production Research Laboratory, ARS-USDA, PO Drawer 10, 2300 Experiment Station Rd, Bushland TX 79012, USA; Tel: 806-356-5769; Fax: 806-356-5750 E-mail: david.brauer@ars.usda.gov increased three-fold in one year from 2002 to 2003 [10]. Lentinan, water-soluble $\beta$-glucan from shiitake, has received considerable attention because of its reported health promoting activities $[7-9,11]$. Shiitakes may contain other glucans with health-promoting properties, but specific constituents have not yet been identified. Marketers of mushroom products often report the polysaccharide content of their mushroom products as an indicator of the products' functional food activity [12]. However, such polysaccharide measurements may not be indicators of functional food activity if shiitake mushrooms or resulting products are high in polysaccharides like starch and glycogen that have little functional food activity [13].

In the past decade information on the carbohydrate content and characteristics of edible mushrooms has increased. In a review of nutritional properties of shiitake, Wasser [14] concludes that approximately $60 \%$ of the dry weight of shiitake mushrooms is total carbohydrate, whereas only $10 \%$ is crude fiber. Similarly, Manzi et al. [15] reported that the total carbohydrates of commonly consumed mushrooms in Italy (Agaricus bisporus, Pleurotus ostreatus and Boletus species) varied between 60 and $70 \%$ of dry weight. Singh $e t$ al. [16] reported that the total carbohydrate fraction of loggrown shiitake mushrooms in India were slightly higher, ranging from 67 to $78 \%$ of dry weight, but the concentration of crude fiber was similar to that in [14], 7 to $8 \%$ of dry weight. Several studies [17-21] have examined the total carbohydrate content of wild edible mushrooms from Portugal and the value for this fraction varied greatly among the species from a low of approximately $10 \%$ in Lepista 
inverse to a high of approximately 55\% in Hygrophoropsis aurantiace. In all of these studies, total carbohydrate was calculated by the difference between dry matter and the sum of crude protein, fat and ash content.

Cellulose and chitin are believed to be important contributors to the total carbohydrate fraction in mushrooms. Jiang et al. [22] found that chitin and cellulose comprised 10 to 20 and 3 to $9 \%$ of the dry weight, respectively. Vetter [23] found similar values for chitin in shiitake mushrooms and reported that the chitin content varied little among different samples.

Water-soluble carbohydrates are usually a minor constituent of mushrooms, representing 1 to $5 \%$ of the dry weight [14]. Reducing sugars tend to be less than $1 \%$ of the dry weight of shiitake mushrooms [14]. Total concentrations of soluble sugars tend to be somewhat higher, averaging between 1 and $5 \%$ of dry weight. Mannitol and trehalose tend to be the dominant soluble sugars in mushrooms [24, 25]. Detectable concentrations of arabinose ( $>0.5 \%$ of dry weight) have been reported in three of ten edible mushroom species collected in Portugal [24]. Soluble sugars were found to be a minor constituent ( $<5 \%$ of dry weight) of ten mushroom species commonly eaten in Korea [25]. It seems unlikely that sugars alone represent the difference between the total carbohydrate fraction and the amount of carbohydrates presented in chitin and cellulose.

Fungi are known to produce glucose based polysaccharides like starch and glycogen, and carbohydrates in these polysaccharides may contribute to the total carbohydrate content. However, there are few reports regarding the starch and/or glycogen content of shiitake mushrooms. Dikeman et al. [26] reported that starch can be relatively abundant in shiitakes. Cooked mature and immature shiitake mushrooms contained slightly more than $20 \%$ of dry weight as starch as determined by amyloglucosidase digestion. Some fungi produce glycogen [27]; however, data on its abundance in shiitakes are lacking. Information on starch and glycogen content in edible mushrooms is generally unavailable. The objective of this study was to provide data on the starch content of log-grown mushrooms produced under a variety of conditions.

\section{MATERIALS AND METHODS}

\section{Log Grown Shiitake Production Method}

Spawn sources were obtained from Field and Forest Products $^{1}$ (Peshtigo, Wisconsin, USA). Many of the tested spawn are not commercially available as of May 1, 2011. Log-grown mushrooms were grown in Shirley, Arkansas, USA (approximately N35.655 W92.318) under typical commercial production methods, which were similar for all of the studies described later. Inoculation was accomplished using sawdust spawn inserted into $1.2 \mathrm{~cm}$ (diameter) x 2.5 $\mathrm{cm}$ (depth) holes drilled into logs in a diamond pattern configuration $(15-22 \mathrm{~cm} \times 4-5 \mathrm{~cm})$. Inoculated holes were then sealed with food-grade cheese-wax heated to approximately $190^{\circ} \mathrm{C}$. Logs averaged approximately $100 \mathrm{~cm}$ in length and 10 to $15 \mathrm{~cm}$ in diameter. Logs were cut green from forest trees after leaf drop in the fall but before bud

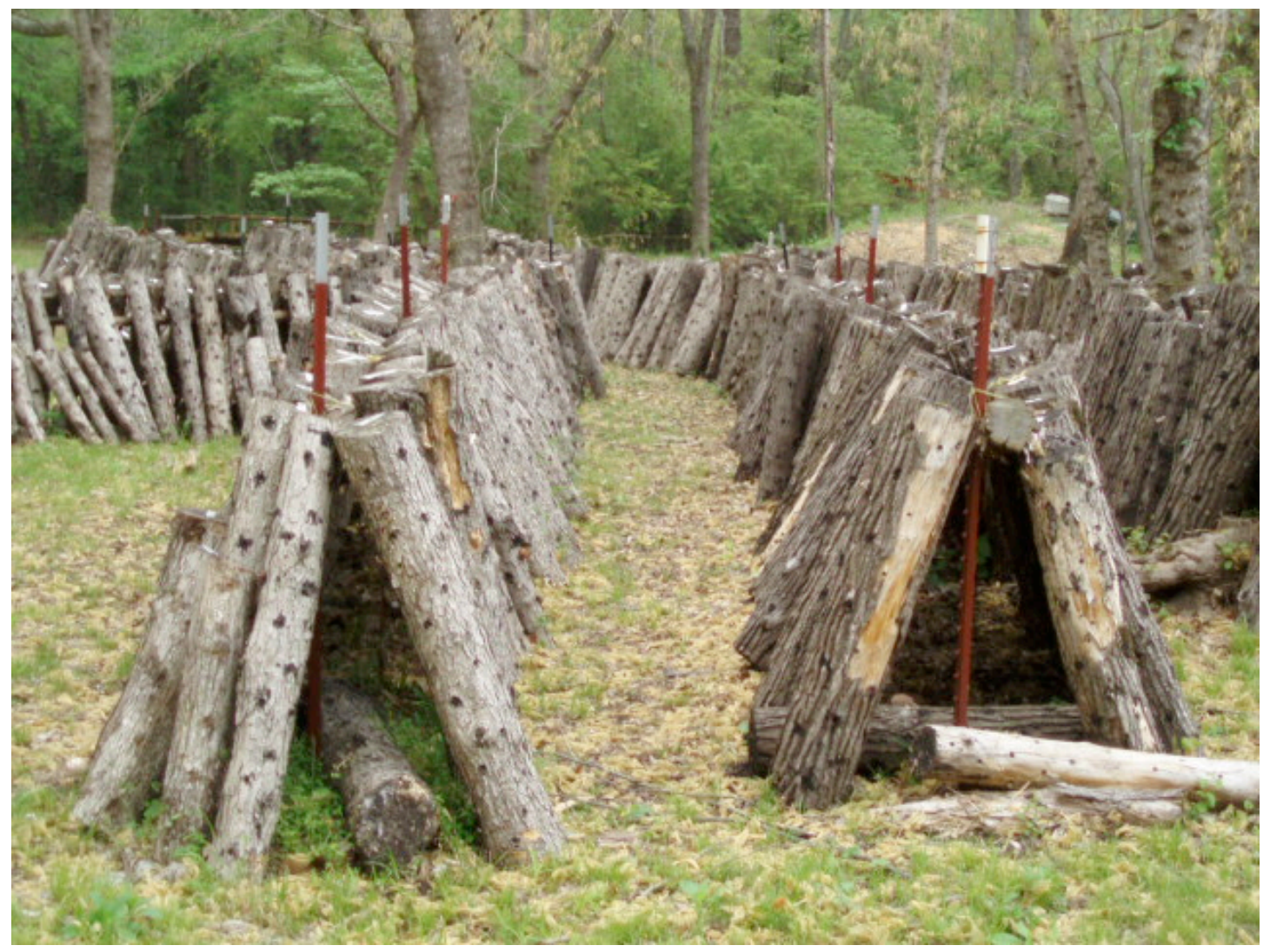

Fig. (1). Logs inoculated with shiitake mushrooms arranged in an A-frame configuration. Logs were inoculated in 2006 (left A-frame) or 2004 (right A-frame). Photograph was made in April 2008 just after harvesting mushrooms for the time after inoculation experiment. 
break in the spring (i.e., mid-November to late March). Except where noted, logs were cut from white oak (Quercus alba L.) trees.

The initial growing conditions involved outdoor incubation in a tight lean-to stack on a northern exposure and covered with Eastern Red Cedar (Juniperus virginiana var. virginiana) boughs to provide approximately $90 \%$ shade. Lean-to stacks were maintained for approximately nine months and hydrated periodically with watering using Rainbird $^{\mathrm{TM}}$ sprinklers (25PJDA-C impact sprinkler, San Diego, California, USA). Initial pinning began typically during the September and October immediately following inoculation. At that time, logs were moved to a denselyshaded, deciduous tree stand and stacked in "A-frames" (Fig. 1). Logs were left in this position to fruit (produce mushrooms) naturally outdoors. Fruiting usually occurred immediately following a heavy rainfall event at suitable ambient temperatures. Mushroom caps typically were collected at one of three development stages: bud, veil break, and open. Bud stage refers to the initial mushroom cap appearance. Buds are formed and visible when the cap is swollen and distinct from its stalk. Buds are usually dome-shaped between 1 and $2 \mathrm{~cm}$ in diameter. Veil break refers to the stage of mushroom development where the universal veil begins to open and separate from the stalk, exposing the gills or lamellae. At veil break, the cap continues to be dome-shaped. The mushroom cap is flat and the outside edges are slightly curled with the gills clearly exposed at the fully open stage. Over 3,000 logs were inoculated for the studies described below. All experiments had three replications with each replication representing over 30 logs.

\section{Shiitake Strain Comparisons}

This study compared the production of starch by 11 shiitake strains growing on white oak logs. Oak logs were inoculated between January 2002 and June 2004 (Table 1) with the intention of obtaining the first harvest of mushrooms in the spring of 2005 and a second harvest in the fall of 2005. Inoculation dates were based on the expected growth rates of the fungal strains. For instance, the cold weather strain, CW-25, was expected to be slow growing; thus, logs inoculated in January 2002 were included in this study. Logs were inoculated in June 2004 with four strains (29-430, 569-430, MY-602 and NN-430) that were expected to have the fastest growth rates. Mushrooms at the veil break stage were collected between September 5 and October 25, 2005, processed, and analyzed for starch [28]. This represented the second mushrooms from these logs.

Starch data were statistically analyzed as a completely randomized block design with shiitake strains as the main effect using PROC GLM of SAS [29]. The F-value for the effects of strains had 10 and 32 degrees of freedom (DF) in the nominator and denominator, respectively. Least square means and standard errors (LSSE) were calculated from PROC GLM [29].

\section{Effects of Log Species Study}

The effects of tree log species on the starch concentrations were assessed with three shiitake strains, Night Velvet, Snowcap, and Westwind and logs harvested from white oak and sweet gum (Liquidambar styraciflua L.) trees. Logs were inoculated between January 2003 and February

Table 1. Summary of the Shiitake Strains and Tree Species Used to Produce Samples. Month and Year (3 Letter Abbreviation for Month, Years between 2002 and 2008) Refers to the Time which at Inoculations and Harvests Occurred

\begin{tabular}{|c|c|c|c|c|c|c|c|}
\hline Strain Name & Temperature Range & Log Species & Inoculation Time & \multicolumn{4}{|c|}{ Harvest Time } \\
\hline Mori 290 & Cold & Oak & Mar-03 & Oct-05 & & & \\
\hline Biyang Flower & Cold & Oak & Apr-03 & Sep-05 & & & \\
\hline $\mathrm{K}-6$ & Wide & Oak & Jan-04 & Sep-05 & & & \\
\hline 762 & Wide & Oak & Jan-04 & Sep-05 & & Sep-05; Oct-06 & \\
\hline $29-430$ & Cold & Oak & Jun-04 & Oct-05 & & Oct-05; Oct-06 & \\
\hline MY-602 & Wide & Oak & Jun-04 & Sep-05 & & Sep-05; Jun-06 & \\
\hline Night Velvet & Warm & Sweet Gum & Jan-03 & & Oct- 05 & & \\
\hline Snowcap & Cold & Oak & Jan-04 & & Sep-05 & & \\
\hline Snowcap & Cold & Sweet Gum & Dec-03 & & Oct-05 & & \\
\hline Westwind & Cold & Oak & Jan-05 & & Oct- 05 & & \\
\hline Westwind & Cold & Sweet Gum & Feb-05 & & Sep-05 & & \\
\hline
\end{tabular}


2005 with one of the three shiitake strains (Table 1). Naturally occurring, flushes for all three strains grown on logs from the two different tree species occurred between September 5, 2005 and October 25, 2005. This flushing represented the second mushroom harvest from these logs. Mushroom samples were collected at bud, veil break, and fully open stages. Samples were processed and analyzed for starch as described below. Analysis of variance was conducted using a completely randomized block design with log species, shiitake strains, and cap development as main effects using PROC GLM of SAS [29]. Least square means and LSSE were used for mean comparisons where F-values were significant at $\mathrm{P} \leq 0.05$.

\section{Mushroom Development/Maturation Studies}

Mushrooms representing bud, veil break, and open developmental stages were collected from the second and third harvests of white oak logs inoculated with one of five shiitake strains (Table 1). The second mushroom harvest from these logs occurred in September and October of 2005. The third harvest began on June 6, 2006 for logs inoculated with strains 569-430 and MY-602; however the other three strains (NN-430, 29-430 and 762) did not being to fruited until October of 2006 (Table 1).

Data from the five strains and two harvests were statistically analyzed using the two harvests as repeated measures, and strains and cap development stage as main effects. Repeated measures analysis of variance was conducted using PROC MIXED of SAS [29]. DF for the main effects of harvests, shiitake strains and stages of mushroom development were 1, 4, and 2 respectively. DF for the error term were 68. Least square means and LSSE were computed by PROC MIXED of SAS [29].

\section{Length of Saprophytic Association Study}

Two shiitake strains were used to inoculate white oak log for an experiment to assess the effects of the length of saprophytic association on starch concentrations. The two strains were 569-430, a wide range strain, and NN-430, a cold weather strain. Logs were inoculated in June of 2004, between January and March of 2006, and December of 2006. Inoculated logs were allowed to fruit in response to existing environmental conditions. Thus, at the beginning of 2008 , logs from these three inoculations represented a range of saprophytic degradation of two to four years. Only mushroom caps in the bud stage were harvested (Table 1) and processed for starch content. Data were analyzed as a completely randomized block design with strains and time after inoculation as main effects using PROC GLM of SAS [29]. Least square means and LSSE were used for mean comparison when F-values indicate a significant effect.

\section{Sample Processing and Polysaccharide Analyses}

Immediately after harvesting, mushrooms were sliced and then dried at room temperature $\left(20\right.$ to $\left.22^{\circ} \mathrm{C}\right)$ with circulating air in an industrial type food drier (Professional Model FD-108, MarVlizer, Madison Wisconsin, USA). Once dry, samples were ground to a powder (20 mesh) using grinding mill (Model 4-E, Straub, Hatboro, Pennsylvania, USA) and stored at $-20^{\circ} \mathrm{C}$ until analyses for polysaccharides. All sam- ples from a harvest period were collected and processed prior to analyses.

Starch concentrations were determined by amyloglucosidase/ $\alpha$-amylase method [16] using the ethanol/water extractant. Further details on the procedure can be found in Brauer et al. [30, 31]. Duplicate determinations were routinely performed on each sample. Additional replicates of analyses were performed until a coefficient of variation among analyses for a sample's starch content was less than $5 \%$. Starch content was not significantly different among sub-samples that were dried either with room temperature air as described above or by lyophilization using a VirTis ${ }^{\mathrm{TM}}$ Benchtop SLC model \#6KBTES-55 apparatus (SP Industries, Gardiner, New York, USA) operating with a vacuum of equal to or less than 0.03 atmospheres and a condenser temperature of $-55^{\circ} \mathrm{C}$ (data not shown). Starch concentrations are expressed on a dry weight basis.

\section{RESULTS AND DISCUSSION}

\section{Shiitake Strain Comparisons}

Starch concentrations in mushrooms collected from 11 strains in the fall of 2005 averaged $50 \mathrm{mg} \mathrm{g}^{-1}$ or $5 \%$ of dry weight. This value is slightly less than reported previously by Dikeman et al. [26], but significantly higher than the values reported by Wasser [14] for water soluble carbohydrates. The higher value here for starch than the previously reported values for water soluble carbohydrates may indicate that some of the starch in shiitake mushrooms are not readily soluble in water. The extraction in the current study included ethanol. A previous study by us indicated that starch values were not significantly different when mushrooms were extracted with water and ethanol or dimethylsulphoxide [31]. The values reported herein for starch indicate that starch is a significant contributor to the total carbohydrate fraction and in greater concentrations than soluble or reducing sugars, which tend to account for less than 5\% if mushroom's dry weight $[14,24,25]$. Concentrations of starch reported here and previously [26] greatly exceeded concentrations previously reported for a lentinan containing fraction $[8,31]$ and $\beta$-glucans [32].

Starch concentrations were significantly affected by shiitake strains for mushrooms harvested starting in the fall of 2005. The F-value from analysis of variance for the effects of strains was $26.36(\mathrm{P}<0.001)$. Concentrations of starch ranged from 21.3 to $92.0 \mathrm{mg} \mathrm{g}^{-1}$ among the 11 strains. Mushrooms from strains Night Velvet, MY-602, 762, and M-290 had the lowest concentrations of starch, averaging $25.3,21.3,27.7$ and $26.5 \mathrm{mg} \mathrm{g}^{-1}$. These means for starch concentrations were not significantly different since the LSSE was $5.0 \mathrm{mg} \mathrm{g}^{-1}$. Starch concentrations in mushrooms were highest with shiitake strains 29-430, and NN-430, and averaged 92.0 and $85.0 \mathrm{mg} \mathrm{g}^{-1}$. Means for the other five strains were between 36.0 and $76.0 \mathrm{mg} \mathrm{g}^{-1}$.

\section{Effect of Log Species}

The starch content of mushrooms harvested in the fall of 2005 was significantly affected by the main effects of log species (sweet gum versus oak) and shiitake strains (Table 2). All interactions among log species, cap development 
stages, and shiitake strains had significant F-values (Table 2).

Table 2. Summary of the Analysis of Variance Examining the Effects of Tree Log Species, Three Shiitake Strains, and Stages of Mushroom Development on Starch Concentrations for Mushrooms Harvested in the Fall of 2005 (Second Harvest)

\begin{tabular}{|c|c|c|c|}
\hline \multirow{2}{*}{ Source of Error } & \multirow{2}{*}{ DF1 } & \multicolumn{2}{|c|}{ Starch Content } \\
\cline { 3 - 4 } & & MSS1 & F-value \\
\hline \hline Tree species of log (L) & 1 & 840.4 & $9.27^{* *}$ \\
\hline Shiitake Strain (S) & 2 & 8942.0 & $98.69^{* * *}$ \\
\hline Development Stage (D) & 2 & 24.5 & 2.59 \\
\hline Log x Developmental stage & 2 & 322.9 & $3.56^{*}$ \\
\hline Log x Strain & 2 & 5071.3 & $55.97^{* * *}$ \\
\hline Strain x Developmental stage & 4 & 2429.9 & $26.82^{* * *}$ \\
\hline L x S x D & 4 & 1233.1 & $13.61^{* * *}$ \\
\hline Error & 36 & 90.6 & \\
\hline
\end{tabular}

${ }^{1}$ Abbreviations: DF, degrees of freedom; MSS; Mean sum of squares.

$2 *, * *$ and $* * *$ denotes that $\mathrm{F}$-value was significant at $\mathrm{P}<0.05,0.01$ and 0.001 , respectively.

Mushrooms from inoculated sweet gum logs had significantly higher concentrations of starch compared to inoculated oak logs, $58.9 \pm 1.8$ (LSSE) compared to $50.8 \pm 1.8$ (LSSE) when data were averaged across three shïtake strains and three stages of cap development. Previous results by us indicated that tree $\log$ species significantly affected concentrations of a fraction that includes lentinan [30]. Mushrooms from logs inoculated with the Westwind shiitake strain highest mean concentration of starch, averaging $75.5 \pm$ $2.2 \mathrm{mg}$ starch $\mathrm{g}^{-1}$ when averaged across two tree log species and three cap developmental stages, whereas logs inoculated with SnowCap had the lowest mean concentration of starch, $30.9 \pm 2.2(\mathrm{LSSE}) \mathrm{mg} \mathrm{g}^{-1}$. Concentrations for Night Velvet

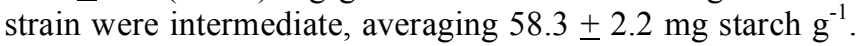
When data were averaged over strains and tree log inoculated, starch concentrations were not significantly affected by developmental stage in this study (Table 2 ).

Although the trends among the main effects were highly significant, there were highly significant interactions among the main effects of tree log species, shiitake strains, and mushroom developmental stage (Table 2). Means in Table 3 capture the complexity of these interactions. When logs from either sweet gum or oak trees were inoculated with the shiitake strain Night Velvet, there were decreases in starch concentrations as mushrooms matured from the bud stage to fully open. Similarly, when sweet gum logs were inoculated with the shiitake strain Westwind, starch concentrations declined as mushrooms matured from veil break to fully open. When oak logs were inoculated with Westwind, starch content increased as mushrooms matured beyond the bud stage. Fully open mushrooms from sweet gum logs inoculated with the shiitake strain Snowcap had higher concentrations of starch than mushrooms harvested at either bud or veil break. Starch concentrations were relatively low in Snowcap mushrooms from oak logs, independent of stage of cap maturation.
Table 3. Interaction among Tree Log Species, Mushroom Development Stage and Shiitake Strain Treatments on Concentrations of Starch in Mushrooms Collected in Fall of 2005 (Second Harvest). Data are Means Across Three Replications. LSSE for Comparing Means in the Table is $5.5 \mathrm{mg} \mathrm{g}^{-1}$

\begin{tabular}{|c|c|c|c|c|}
\hline \multirow{2}{*}{ Shiitake Strain } & \multirow{2}{*}{ Log Species } & \multicolumn{3}{|c|}{ Starch Content } \\
\cline { 3 - 5 } & & \multicolumn{3}{|c|}{ Development Stage } \\
\cline { 3 - 5 } & & \multicolumn{3}{|c|}{ mg g-1 } \\
\cline { 3 - 5 } & \multirow{2}{*}{ Sweet Gum } & 86.3 & 72.0 & 65.7 \\
\hline \hline Night Velvet & Oak & 67.3 & 25.3 & 33.0 \\
\hline Night Velvet & Sweet Gum & 63.3 & 66.7 & 50.3 \\
\hline Westwind & Oak & 71.0 & 109.5 & 92.3 \\
\hline Westwind & Sweet Gum & 17.7 & 20.3 & 87.7 \\
\hline Snowcap & Oak & 15.3 & 19.3 & 25.3 \\
\hline Snowcap & & &
\end{tabular}

\section{Shiitake Mushroom Development/Maturation Studies}

The effects of development stage of the mushroom on the concentrations of starch were further studied in an experiment, in which mushrooms from five strains and two harvests were analyzed. In this experiment, starch concentrations were significantly $(\mathrm{P}<0.001)$ affected by the main effects of harvests $(\mathrm{F}$-value $=7.76)$, shiitake strains $(\mathrm{F}$-value $=54.1$ ), and developmental stages of the mushroom (F-value $=10.3$ ). The interaction between strains and developmental stages was also significant $(\mathrm{F}$-value $=4.6 ; \mathrm{P}<0.01)$. The overall mean for starch concentration in the third harvest was significantly lower than for the second harvest, 48.2 versus $30.1 \mathrm{mg} \mathrm{starch} \mathrm{g}^{-1}\left(\mathrm{LSSE}=1.4 \mathrm{mg} \mathrm{g}^{-1}\right)$.

In general, across the three cap developmental stages, starch concentrations tended to be least when mushrooms were in the bud stage. Starch concentrations in the bud, veil break and fully open stages averaged $32.5,43.5$ and $41.5 \mathrm{mg}$ $\mathrm{g}^{-1}$, respectively (LSSE $=1.7 \mathrm{mg} \mathrm{g}^{-1}$ ) across the five strains. Similarly, Valdez-Morales et al. [33] reported that the carbohydrate content of huitlacoche (Ustilago maydis) varied with developmental stage of the fungi. Barros et al. [18] reported significant declines in total carbohydrates as fruiting bodies mature.

There was significant interaction between strain and developmental stage in this study. This interaction appears to originate from the fact that the starch content of mushrooms from strain 29-430 varied little with developmental stages, and in the other four strains starch content of mushrooms of were least in the bud stage.

\section{Length of Saprophytic Association Study}

The concentrations of starch in mushrooms collected at the bud break developmental stage in the spring of 2008 were significantly affected by length of the saprophytic association and the shiitake strain used to inoculate the logs (Table 4). Mushrooms from strain 569-430 had lower concentrations of starch than $\mathrm{NN}-430$ when averaged across 
time after inoculation (26.7 and $44.3 \mathrm{mg} \mathrm{g}^{-1}$; LSSE of $0.6 \mathrm{mg}$ $\left.\mathrm{g}^{-1}\right)$.

Table 4. Analysis of Variance Summarizing the Effects of Length of Saprophytic Association and Shiitake Strains on Starch Concentrations in Mushrooms Harvested at the Bud Break Stage in the Spring of 2008

\begin{tabular}{|c|c|c|c|}
\hline \multirow{2}{*}{ Source of error } & \multirow{2}{*}{ DF1 } & \multicolumn{2}{|c|}{ Starch Content } \\
\cline { 3 - 4 } & & MMS1 & F-value \\
\hline \hline Length of Association & 2 & 65.56 & $21.82^{* * *}$ \\
\hline Shiitake Strain & 1 & 1395.68 & $464.45^{* * *}$ \\
\hline Association Length x Strain & 2 & 84.99 & $28.28^{* * *}$ \\
\hline Error & 12 & 1732.85 & \\
\hline
\end{tabular}

Abbreviations: DF, degrees of freedom; MSS; Mean sum of squares.

$* * *$ denotes that $\mathrm{F}$-value was significant at $\mathrm{P}<0.001$.

When averaged across the two strains, starch concentrations decreased with increasing age of the saprophytic association. Caglarirmak [24] reported that crude protein content decreased with increasing harvests of Agraicus bisporus. However, the changes in starch concentrations with age or length of association were quite different between the two shiitake strains (Fig. 2). There was a substantial and prog-

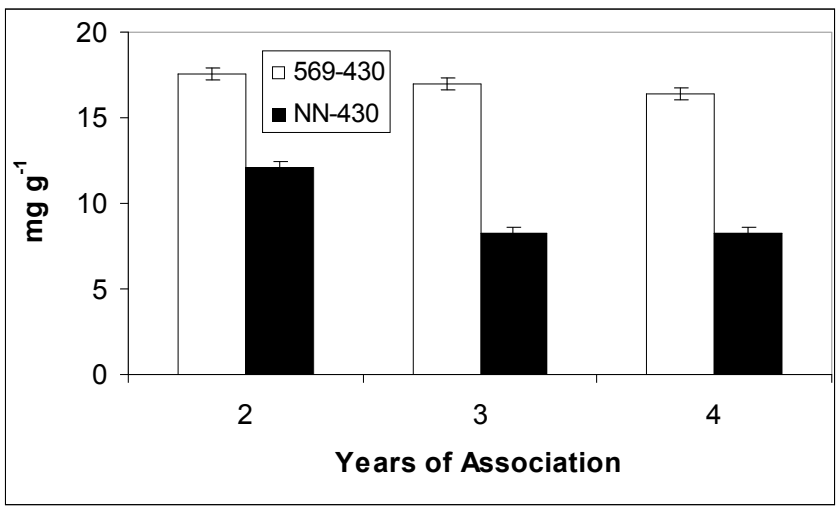

Fig. (2). Effects of length of saprophytic association on starch concentrations $\left(\mathrm{mg} \mathrm{g}^{-1}\right)$ in mushrooms from two shiitake strains harvested in the bud break stage. Data from 569-430 and NN-430 are presented by open and solid bars, respectively. Bars representing the LSSE are presented. Mushrooms were harvested in the spring of 2008 from logs inoculated in June 2004, January 2006 or December 2006, resulting in lengths of saprophytic associations of two, three or four years, respectively.

ressive decline in starch concentrations with time after inoculation of $\operatorname{logs}$ with strain NN-430. Ahmend et al. [34] reported that the total carbohydrate fraction of Pleurotus florida (Mont.) increased as the fungi's substrate composition was altered. Therefore, the change in starch concentration in mushroom of strain $\mathrm{NN}-430$ could reflect a change in the substrate available to the fungi as degradation of the tree log progressed. Starch concentrations of mushrooms of 569-430 peaked three years after inoculation with values after two and four years being very similar.

\section{CONCLUSIONS}

These results indicate that starch can be a significant component of shiitake mushrooms. Maximum starch concentrations observed in these studies exceeded $110 \mathrm{mg} \mathrm{g}^{-1}$ dry weight or approximately $10 \%$ of the mushroom's mass. This level of starch is consistent with the previous report [26].

The results from this study also indicate that the concentrations of starch in shiitake mushrooms are influenced to a large degree by the fungal strains and the characteristics of the environment. Variations in starch content among shiitake strains varied over four-fold from lowest to highest levels during a fruiting. Characteristics of the environment including tree species used as substrate, mushroom cap development, and length of time after inoculation influenced starch concentrations. Despite the observed phenotype-environment interactions, some generalizations were revealed: 1) in most cases, as shiitake mushroom caps matured beyond the bud break stage, starch concentrations were higher; and 2) starch concentrations tended to decrease as the length of the saprophytic association increased.

\section{FOOTNOTE}

${ }^{1}$ Mention of trade names or commercial products in this article is solely for the purpose of providing specific information and doe not imply recommendation or endorsement by the U.S. Department of Agriculture.

\section{ACKNOWLEDGEMENTS}

Expenses for part of the research conducted in this article were defrayed by a specific cooperative agreement (\#586227-4-017) between ARS and the Shirley Community Development Corporation.
ABBREVIATIONS
$\mathrm{DF} \quad=$ Degree of freedom
LSSE $=$ Least square standard errors
MSS = Mean sum of squares

\section{REFERENCES}

[1] National Agricultural Statistics Service. Mushrooms (Annual Publication); U.S. Department of Agriculture, Crop Reporting Board, Economics, Statistics, and Cooperatives Service 2001.

[2] Underwood A. The Magic of Mushrooms. Newsweek 2003; vol. 142 , p. 61 .

[3] Johnson \& Johnson Consumer Companies, Inc. [homepage on the Internet]. 2005-2010 [updated: December 1, 2010; cited: December 9, 2010]. Discover the Science of Active Naturals, Natural shiitake. Available from: http://www.aveeno.com/active-naturals/shiitake

[4] Rodman Publishing. [homepage on the Internet] Uncloaking the mysteries of medicinal mushrooms by Adams, C. in Nutraceuticals World. [updated: December 9, 2010; cited: December 11, 2009] Available from: http://www.nutraceuticalsworld.com/issues/ archive/

[5] National Agricultural Statistics Service. Mushrooms (Annual Publication); U.S. Department of Agriculture, Crop Reporting Board, Economics, Statistics, and Cooperatives Service. 2009. Available from: http://usda.mannlib.cornell.edu/usda/current/ Mush/Mush-08-20-2009.pdf. Cited December 11, 2009.

[6] Ooi VEC, Liu F. Immumomodulation and anti-cancer activity of polysaccharide-protein complexes. Curr Med Chem 2000; 7: 715-9. 
[7] Chang R. 1996. Functional properties of edible mushrooms. Nutr Rev 1996; 54(11): S91-S93.

[8] Geslewitz G. Immune support products: a mushrooming category. Vit Retailer 2003; 30-4.

[9] Mizuno T, Sakai T. Health foods and medicinal usages of mushrooms. Food Rev Int 1995; 11(1): 69-81.

[10] Zeisel SH. Regulation of nutraceuticals. Science 1999; 285(5435): 1853-5.

[11] Jong SC, Birmingham JM. Medicinal and therapeutic value of the shiitake mushroom. Adv Appl Microbiol 1993; 39: 153-84.

[12] The mushroom patch. [homepage on the Internet] Medicinal mushroom powder. [updated: January 1, 2008; cited: January 12, 2009] Available from: http://mushroompatch.com/herbal_powder. htm

[13] Sadler M. Nutritional properties of edible fungi. Br Nutr Found Nutr Bull 2003; 28: 305-8.

[14] Wasser SP. Shiitake (Lentinus edodes). In Encyclopedia of Dietary Supplements. New York, USA: Marcel Dekker 2005; pp. 653-665. DOI: $10.1081 /$ E-EDS-120024880.

[15] Manzi P, Aguzzi A, Pizzoferrato L. Nurtitional value of mushrooms widely consumed in Italy. Food Chem 2001; 73: 321-5.

[16] Singh HB, Adhikary RK, Sharma RK, Sarma TC, Rao PG. Cultivation of shiitake mushroom- A potential agro-industry for hilly areas of north eastern India. Ind J Nat Prod Resour 2008; 7 : 74-8.

[17] Barros L, Bapista P, Correia DM, Morais JS, Ferreira ICFR. Effects of conservation treatment and cooking on the chemical composition and antioxidant activity of Portuguese wild edible mushrooms. J Agric Food Chem 2007; 55: 4781-8.

[18] Barros L, Bapista P, Estevinho LM, Ferreira ICFR. Effect of frutiing body maturity stage on chemical composition and antimicrobial activity of Lactarius sp. mushrooms. J Agric Food Chem 2007; 55: 8766-71.

[19] Barros L, Cruz T, Bapista P, Estevinho LM, Ferreira ICFR. Wild and commercial mushrooms as source of nutrients and nutraceuticals. Food Chem Toxicol 2008; 46: 2742-7.

[20] Barros L, Venturini BA, Bapista P, Estevinho LM, Ferreira ICFR. Chemical composition and biological properties of Portuguese wild mushrooms: a comprehensive study. J Agric Food Chem 2008; 56: 3856-62.

[21] Heleno SA, Barros L, Sousa MJ, Martins A, Ferreira ICFR. Study and characterization of selected nutrients in wild mushrooms from Portugal by gas chromatography and high performance liquid chromatography. Microhchem J 2009; 93: 195-9.
[22] Jiang T, Wang Q, Xu S, Jahangir MM, Ying T. Structure and composition in the cell wall in relations to texture of shiitake mushrooms (Lentinula edodes) stored in modified atmosphere packaging. J Sci Food Agric 2010; 90: 742-9.

[23] Vetter J. Chitin content of cultivated mushrooms Agaricus bisporus, Pleurotus ostreatus and Lentinula edodes. Food Chem 2007; 102: 6-9.

[24] Caglarirmak N. 2009. Determination of nutrients and volatile constituents of Agaricus bisporus (brown) at different stages. J Sci Food Agric 2009; 89: 634-8.

[25] Kim M-Y, Chung I-M, Lee S-J, et al. Comparison of free amino acids, carbohydrate concentrations in Korean edible and medicinal mushrooms. Food Chem 2009; 113: 386-93.

[26] Dikeman CL, Bauer LL, Flickinger EA, Fahey GC Jr. Effects of stage of maturity and cooking on the chemical composition of select mushroom varieties. J Agric Food Chem 2005; 53(4): 11308.

[27] Well TK, Hammond JBW, Dickerson AG. Variations in activities of glycogen phosphorylase and trehalase during the periodic fruiting of the edible mushroom Agaricus bisporus (Lange) Imbach. New Phytol 1987; 105(2): 273-80.

[28] Megazyme International Ireland Limited. [homepage on internet] Total Starch Assay Procedure (AMYLOGLUCOSIDASE/ $\alpha$ AMYLASE METHOD). [Available from http://www.megazyme. com/downloads/en/data/K-TSTA.pdf. Verified December 12, 2009.

[29] SAS [Computer Program]. Version 9.1. Cary (NC): SAS Institute. 2002.

[30] Brauer D, Kimmons T, Phillips M. Effects of management on the yield and high-molecular-weight polysaccharide content of shiitake (Lentinula edodes) mushrooms. J Agric Food Chem 2002; 50(19): 5333-7.

[31] Brauer D, Kimmons T, Phillips M. Comparison of two methods for the quantitation of $\beta$-glucans from shiitake mushrooms. J Herbs Spices Med Plants 2007; 13(3): 15-26.

[32] Manzi P, Pizzoferrato L. Beta-glucans in edible mushrooms. Food Chem 2000; 68(3): 315-8.

[33] Valdez-Morales M, Barry K, Fahey GC, et al. Effect of maize genotype, developmental stage and cooking process on the nutraceutical potential of huitlacoche (Ustilago maydis). Food Chem 2010; 119: 689-97.

[34] Ahmed SA, Kadam JA, Mane VP, Patil SS, Baig MMV. Biological efficiency and nutritional contents of Pleurotus florida (Mont.) Singer Cultivated on Different Agro-wastes. Nat Sci 2009; 7(1): 44-8.

Received: December 18, 2010

Revised: March 16, 2011

Accepted: May 18, 2011

(C) Brauer et al.; Licensee Bentham Open.

This is an open access article licensed under the terms of the Creative Commons Attribution Non-Commercial License (http://creativecommons.org/licenses/by$\mathrm{nc} / 3.0 /$ ), which permits unrestricted, non-commercial use, distribution and reproduction in any medium, provided the work is properly cited. 